\title{
INFLUENCE OF COMBINED PHARMACOTHERAPY ON CARDIO-VASCULAR SYSTEM OF ARTERIAL HYPERTENSION (IN EXPERIMENT)
}

DOI: $10.36740 /$ WLek202008123

\author{
Svetlana N. Chuhray' ${ }^{1}$ Viktoria E. Lavrynenko ${ }^{2}$, Ruzhena M. Matkivska', Tetiana V. Lachtadyr', \\ Valentina M. Hamaliii ${ }^{3}$, Rostyslav F. Kaminsky' ${ }^{1}$, Oleksandr I. Kovalchuk ${ }^{1,2}$, Liudmyla M. Sokurenko ${ }^{1,2}$ \\ 'BOGOMOLETS NATIONAL MEDICAL UNIVERSITY, KYIV, UKRAINE \\ ${ }^{2}$ TARAS SHEVCHENKO NATIONAL UNIVERSITY OF KYIV, KYIV, UKRAINE \\ ${ }_{3}^{3}$ KYIV CITY CLINICAL EMERGENCY HOSPITAL, KYIV, UKRAINE
}

\begin{abstract}
The aim: Study of the patterns of structural changes in the left ventricular myocardial capillaries of rats with arterial hypertension with combined pharmacotherapy with Bisoprolol and Thiotriazolinum.

Materials and methods: Experiments were conducted on 30 line rats with congenital stress-induced arterial hypertension: 10 animals without treatment and 10 animals with treatment. Pharmacological correction of spontaneous arterial hypertension was performed with $20 \mathrm{mg} / \mathrm{kg}$ of Bisoprolol and $50 \mathrm{mg} / \mathrm{kg}$ of Thiotriazolinum per os once a day. Pharmacotherapy began at 5 months of age, that is, at a time when compensated heart failure was formed in rats with arterial hypertension. Animals were withdrawn from the experiment 100 days after the start of the correction. Control was provided by intact animals ( $10 \mathrm{rats}$ ) of the corresponding age. While extracted from the experiment rats of all experimental groups had their arterial pressure measured using a plethysmograph, electron microscopic examination of the left ventricular myocardium and morphometric study of volumetric and quantitative densities, cross-section area and form factor of micropinocytotic vesicles were conducted.

Results: In rats with arterial hypertension after application of Bisoprolol and Thiotriazolinum, arterial pressure significantly decreases in experimental rats compared to animals without correction. The number of capillaries in the myocardium after pharmacotherapy increases up to control values, which shows their reparation. In most endothelial cells, organelles retain their integrity and presence that are characteristic of intact rats. The well-expressed processes of transcytosis are shown by the statistical similarity of the quantitative density and the size of the micropinocytotic vesicles in the endothelial cells of the myocardium capillaries of compared experimental animals.

Conclusions: In rats with arterial hypertension, the combination of Bisoprolol and Thiotriazolinum prevents the decrease in the number of capillaries in the myocardium of the left ventricle, promotes the preservation of the ultrastructure of their endothelial cells and maintains the processes of transedothelial transfer of substances at the level of intact animals.
\end{abstract}

KEY WORDS: myocardium, blood capillaries, rat, hypertension, electron microscopy, Thiotriazolinum, Bisoprolol

Wiad Lek. 2020;73(8):1712-1716

\section{INTRODUCTION}

As increased arterial blood pressure (ABP) has long been mentioned in the medical literature $[1,2,3,4]$, the issue of correction of arterial hypertension of various genesis remains relevant. Despite the rapid development of pharmacotherapy, it improves the quality of life of patients but does not always prevent negative changes in myocardium and blood vessels. In addition, in the use of antihypertensive drugs there are side effects, which worsen the effectiveness of correction of patients with this pathology. Despite numerous publications on the structural effects of antihypertensive therapy, it is not known which conditions contribute to the improvement of the structure of the microvessels [5].

Consequently, the definition of the structural foundations for the development of pathological changes in the blood capillaries and the possibilities of their pharmacological correction will serve as a theoretical basis for the development of new approaches to the correction of arterial hypertension.

\section{THE AIM}

The aim of the study was to analyze the patterns of structural changes in the left ventricular myocardial capillaries of rats with arterial hypertension with combined pharmacotherapy with Bisoprolol and Thiotriazolinum.

\section{MATERIALS AND METHODS}

Experiments were performed on 30 white rats, which were under standard vivarium conditions of the Bogomolets National Medical University. The rats (hereditary stress-induced arterial hypertension line) with AH (arterial hypertension) were studied [6]: 10 with and 10 without treatment. Control was provided by intact rats of the Wistar line of the same age.

Pharmacological correction of arterial hypertension was performed with Bisoprolol (ZAO "Borshchagovsky Ch$\mathrm{PhP}$ ", Ukraine) at a dose of $20 \mathrm{mg} / \mathrm{kg}$ and Thiotriazolinum (Pharmacon Pharmacy, Ukraine) at a dose of $50 \mathrm{mg} / \mathrm{kg}$. The solvent for both drugs was water. Pharmacotherapy of rats with arterial hypertension began at the age of 5 months, 
that is, at a time when compensated heart failure was formed in rats with arterial hypertension [7,8]. Drugs were administered per os once a day. Animals were withdrawn from the experiment 100 days after the start of correction.

Bisoprolol belongs to a group of $\beta$-blockers, which are widely used in the world for the correction of arterial hypertension [9]. Thiotriazolinum is a drug of metabolic action, the feature of which is the ability to increase the energy-saving and energy-assimilating functions of cells and thus protect them $[10,11,12]$.

Experiments with animals were carried out in accordance with the Law of Ukraine "On protection of animals from cruelty" (2006), "General ethical principles of animal experiments", adopted by the First National Congress on Bioethics (Kiev, 2001) and in accordance with the requirements of the "European Convention for the Protection of Vertebrate Animals Used for Experimental and other Scientific Purposes" (Strasbourg, 1985).

Measuring of arterial pressure, morphometric studies, electron microscopic examination were conducted as in the previous article on the study of cardio-vascular system $[13,14,15]$.

While extracted from the experiment rats of all experimental groups had their AP (arterial pressure) measured using a plethysmograph.

The structure of myocardium of the left ventricle in rats from experimental group was studied using electron microscopy. The material for examination was processed according to the general techniques of electron microscopic studies [16]. Ultra-thin sections were produced by ultratome Reihart (Austria) and analyzed under the electron microscope PEM-125K.

The tissues were morphometrically analyzed on semi-automatic equipment for processing of graphic research. The program "Organelle" was used. Cross-section areas, form factor of micropinocytotic vesicles as well as their volumetric and quantitative densities were used as criteria in our study. Student parametric and Kolmogorov-Smirnov nonparametric criteria were used for statistical processing of received data according to variation statistics principle.

\section{RESULTS}

\section{CHANGES IN FUNCTIONAL PARAMETERS IN RATS WITH CORRECTION AND WITHOUT IT}

In rats with arterial hypertension after application of Bisoprolol and Thiotriazolinum, arterial pressure significantly decreases in experimental rats in comparison with animals without correction and does not statistically differ from the pressure of control rats of the same age. It is $122.5 \pm 3.9 \mathrm{~mm} \mathrm{Hg}$.

\section{ULTRASTRUCTURE OF BLOOD CAPILLARIES OF MYOCARDIUM IN RATS WITH CORRECTION AND WITHOUT IT}

Electron microscopic analysis of the left ventricular myocardium in rats with arterial hypertension after the use of Bisoprolol in combination with Thiotriazolinum showed

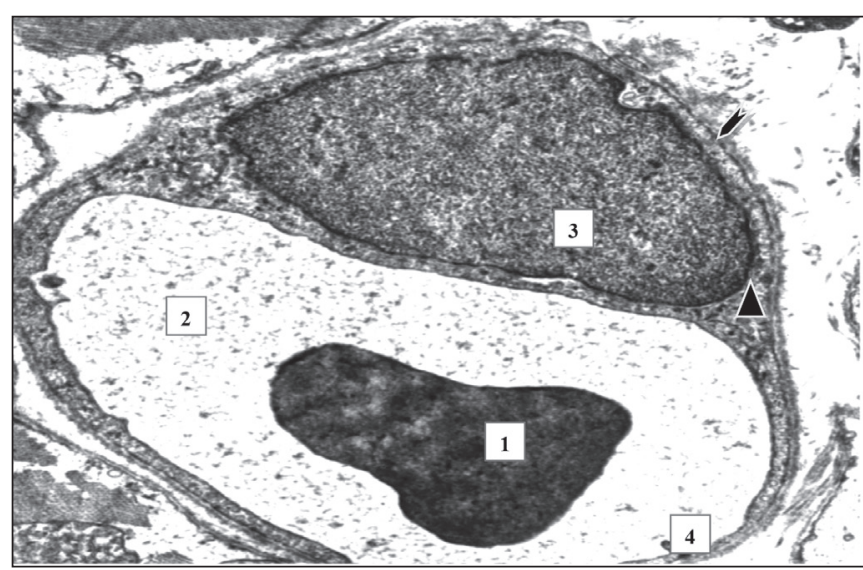

Fig.1. Blood capillaries of the left ventricle myocardium of rats with arterial hypertension with influence of Bisoprolol and Thiotriazolinum. Electron microscopic photo. Magnification: 17000. Erythrocyte (1) in the lumen (2) of the capillary. Nucleus (3), micro-outgrowths (4), micropinocytotic vesicles ( $\boldsymbol{\Delta})$ in endothelial cell. Basement membrane ().

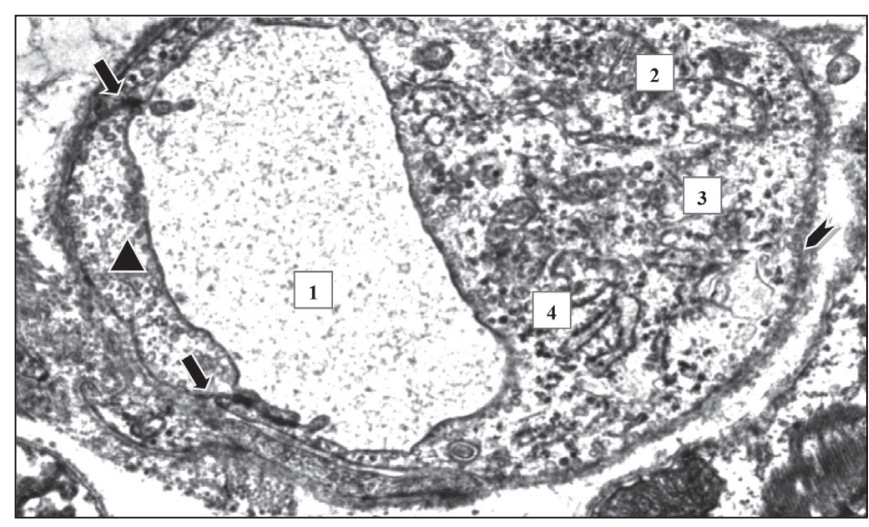

Fig.2. Blood capillaries of the left ventricle myocardium of rats with arterial hypertension with influence of Bisoprolol and Thiotriazolinum. Electron microscopic photo. Magnification: 1800. Lumen (1) of the capillary. Mitochondria (2), Golgi body (3), ER cisternae (4), micropinocytotic vesicles $(\mathbf{\Delta})$ in endothelial cells. Basement membrane ( ).

that despite the preservation of some changes in the structure of the myocardium's blood capillaries inherent in hypertensive rats, a significant improvement in their structural organization is noted. The lumen surface of the endothelium is smooth, contains a moderate amount of shallow invaginations and micro-outgrowths (Fig.1, Fig. 2).

Nucleus-bearing zones do not protrude in the lumen, peripheral regions have moderate thickness, but sometimes they are thinned to the size of one or two micropinocytotic vesicles. The nuclei of such endothelial cells are oval, somewhat elongated, have smooth surface without pronounced invaginations. Nuclear envelope is well-structured. In the karyoplasm, there is evenly distributed chromatin, among which the transcriptionally active form - euchromatin predominates. Perinuclear space is not extended (Fig.1).

Organelles of the biosynthetic plan - ribosomes, polysomes, Golgi complex and rough endoplasmic reticulum cisternae and mitochondria - are present in an increased number compared 


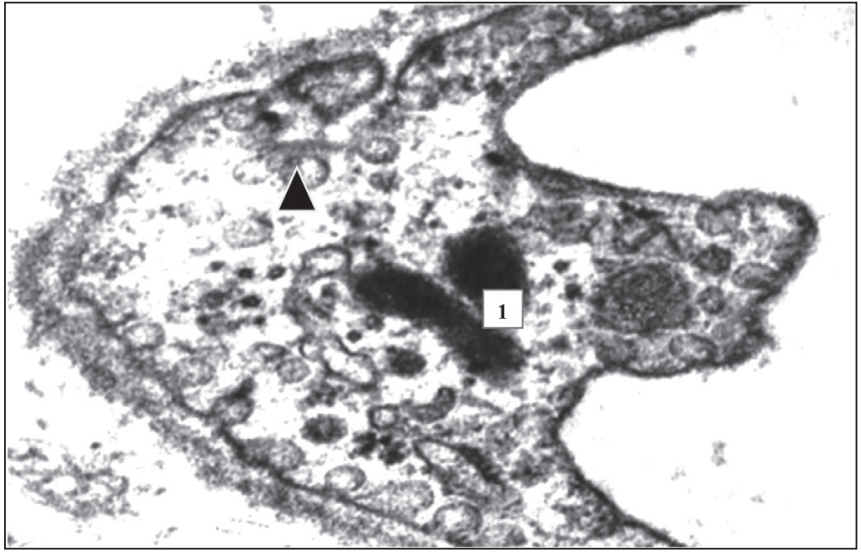

Fig. 3. Blood capillaries of the left ventricle myocardium of rats with arterial hypertension with influence of Bisoprolol and Thiotriazolin. Electron microscopic photo. Magnification: 60000. Micropinocytotic vesicles $(\boldsymbol{\Delta})$,Weibel-Palade bodies (1) in endothelial cell.

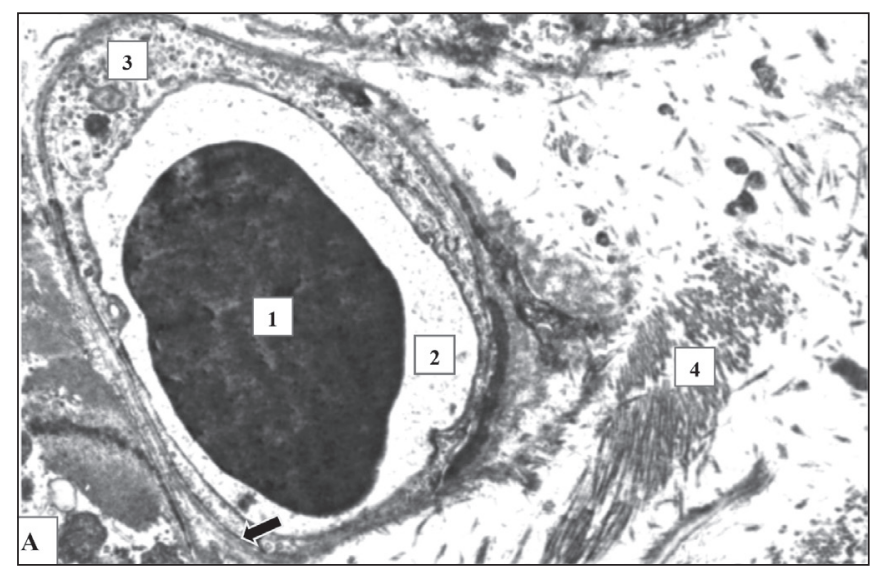

Fig. 4. Blood capillaries of the left ventricle myocardium of rats with arterial hypertension with influence of Bisoprolol and Thiotriazolinum. Electron microscopic photo. Magnification: 12000. Erythrocyte (1) in the lumen (2) of the capillary. Cytoplasm (3), inter-endothelial junctions $(\swarrow)$ in endothelial cells. Collagen fibers (4) in perivascular space.

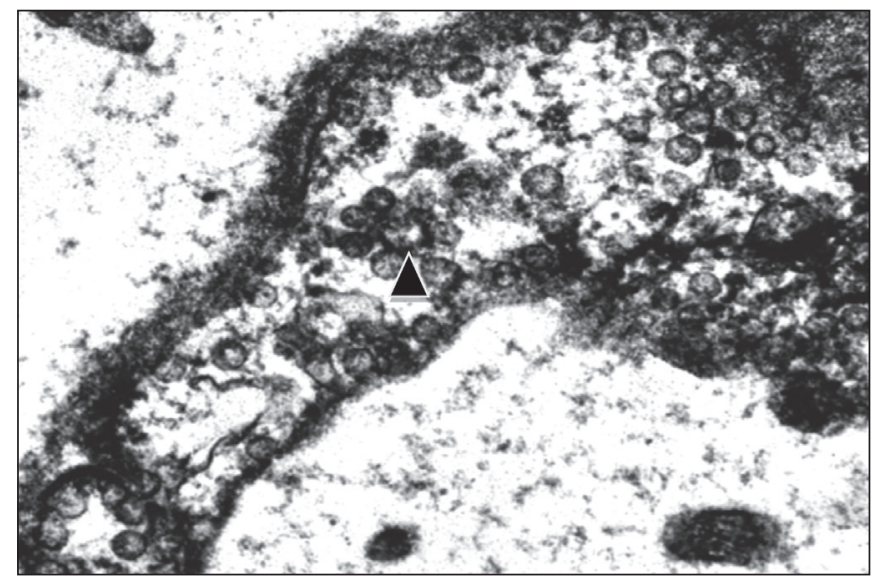

Fig.5. Blood capillaries of the left ventricle myocardium of rats with arterial hypertension with influence of Bisoprolol and Thiotriazolinum. Electron microscopic photo. Magnification: 60000 . Accumulation of micropinocytotic vesicles $(\boldsymbol{\Delta})$ in endothelial cells. with animals without correction. They are located mainly around the nucleus, but are observed in peripheral areas as well. Mitochondria have different shapes and sizes, among which large, hypertrophied forms predominate. They are surrounded by a well-structured integral outer membrane, have a matrix of moderate electron density, in which there are crystaes, the number of which varies in different organelles (Fig. 1). Rough endoplasmic reticulum cisternae predominate. Everywhere there are different sizes of moderately expanded cisternae with a significant amount of ribosomes on their membranes (Fig. 2). The ribosomal apparatus in the form of both separate structures and the polysomes is located throughout the cytoplasm (Fig. 2). Complex Golgi has moderately advanced cisternae (Fig. 2).

Characteristic is the appearance of Weibel-Palade bodies (Fig.3), which was not observed in animals without correction, indicating the activation of the synthesis of biologically active substances. Lysosomes and lipid inclusion are rare. The cytoskeleton in endothelial cells is represented mainly by microfilaments, which are located throughout the cytoplasm.

Endothelial cells are interconnected with different lengths of junctions, most of which are short joints (Fig.1, Fig.2).

At the same time, cells with electron-enlightened cytoplasm of varying degrees are observed. These cells contain a small number of biosynthetic plan organelles with ultrastructural signs of damage, local lysis of mitochondria, edema of endoplasmic reticulum cisternae and transport structures - micropinocytotic vesicles (Fig.4). Often, on the surface of these cells, there are microclasmatic outgrowths that desquamate into the lumen.

As for the basement membrane, presence of areas of uneven thickening, loosening, even in well-preserved capillaries should be noted (Fig.1, Fig.2). The number of collagen fibers in the perivascular space is not significantly reduced compared to animals without correction (Fig. 4).

\section{MICROPINOCYTOTIC VESICLES IN ENDOTHELIAL CELLS OF MYOCARDIAL BLOOD CAPILLARIES IN RATS WITH CORRECTION AND WITHOUT IT}

Micropinocytotic vesicles vary in number even within a single cell. Areas of cytoplasm filled with micropinocytotic vesicles alternate with sites where there is a small amount of them (Fig. 5). Micropinocytotic vesicles can be found attached to the basal, or lumen membranes and as detached units. In certain areas they form multivesicular clusters and branched chains, sometimes attached to membranes in the junction zones. The morphometric analysis showed statistical homogeneity of the quantitative density and size of the micropinocytotic vesicles in the endothelial cells of the myocardium capillaries with control values and the difference from the indexes in animals without correction (Table I).

\section{DISCUSSION}

In rats with arterial hypertension after the administration of Bisoprolol and Thiotriazolinum, the arterial pressure in the experimental animals significantly decreases in com- 
Table I. The morphometric indexes of micropinocytotic vesicles in endothelial cells of myocardial circulatory capillaries

\begin{tabular}{|c|c|c|c|c|}
\hline Groups & Volumetric density, \% & $\begin{array}{l}\text { Quantitative density, } \\
\qquad 1 / \mu \mathrm{m}^{3}\end{array}$ & $\begin{array}{l}\text { Average area, } \\
10^{-2} \mu^{2}\end{array}$ & Form factor \\
\hline Control & $16,81 \pm 2,16$ & $335,3 \pm 71,7$ & $0,52 \pm 0,02$ & $0,78 \pm 0,01$ \\
\hline $\mathrm{AH}$ & $9,66 \pm 1,01 *$ & $56,5 \pm 7,2 *$ & $1,17 \pm 0,03^{*}$ & $0,83 \pm 0,01$ \\
\hline $\mathrm{AH}$ and correction & $15,08 \pm 1,71^{* *}$ & $287,4 \pm 53,1^{* *}$ & $0,49 \pm 0,03^{* *}$ & $0,77 \pm 0,01^{* *}$ \\
\hline
\end{tabular}

Note: ${ }^{*}-p<0,05$ in comparison with the data of the Control;

** $-p<0,05$ in comparison with the data of the group without correction.

parison with non-corrected ones and does not statistically differ from that of control rats of the same age. It is $122.5 \pm$ $3.9 \mathrm{~mm} \mathrm{Hg}$. The number of capillaries in the myocardium after the pharmacotherapy not only does not decrease, as it is observed in 240-day-old animals without correction, but also increases up to control values, implying their reparation. In most endothelial cells, organelles retain their integrity and presence that are characteristic of intact rats. The well-expressed processes of transcytosis are shown by the statistical similarity of the quantitative density and size of micropinocytotic vesicles in the endothelial cells of the myocardium capillaries of the compared experimental animals.

The expression of biosynthetic processes in capillary endothelial cells of rats with arterial hypertension at correction, most likely, is a manifestation of the influence of Thiotriazolin, which, by increasing biosynthetic activity, promotes the regeneration of cells and their organelles $[17,18]$. Particular attention is drawn to the presence of Weibel-Palade bodies in the endothelial cells of the blood capillaries, which is associated with the increased synthesis of biologically active substances. It should be noted that part of endothelial cells in capillaries of rats with arterial hypertension during the correction retains dystrophic-destructive signs. This may be due to the fact that antihypertensive therapy does not always normalize the structure of resistant vessels, despite the normalization of blood pressure, since blood pressure is not the only factor that determines the structure of these vessels [19].

Pharmacological agents vary in the ability to reverse structural and functional changes in hemo-microcirculation [20]. Obviously, for the restoration of normal hemo-microcirculation and reduction of capillary dilution it is expedient to use antihypertensive drugs with different orientations, which would act synergistically [21].

\section{CONCLUSIONS}

In rats with arterial hypertension, the combination of $\mathrm{Bi}-$ soprolol and Thiotriazolinum prevents the decrease in the number of capillaries in the myocardium of the left ventricle, promotes the preservation of the ultrastructure of their endothelial cells and maintains the processes of transedothelial transfer of substances at the level of intact animals.

Confirmation of the latter is the statistical homogeneity of the quantitative density of micropinocytotic vesicles in endothelial cells after pharmacological correction with the control value and a significant difference from the indicator in animals without correction.

\section{REFERENCES}

1. Schunkert H. Management der arteriellen Hypertonie. Herz. 201843 : 695. https://doi.org/10.1007/s00059-018-4758-3

2. Finocchi C., Sassos D. Headache and arterial hypertension Neurol Sci. 2017: 38(Suppl 1): 67. https://doi.org/10.1007/s10072-017-2893-x

3. Rimoldi S.F., Scherrer U., Messerli F.H. Secondary arterial hypertension: when, who, and how to screen? European Heart Journal. 2014; 35(19): 1245-1254. https://doi.org/10.1093/eurheartj/eht534

4. Kallistratos M.S., Poulimenos L.E., Manolis A.J. Atrial fibrillation and arterial hypertension. Pharmacological Research. 2018; 128: 322-326.

5. Christensen K.L., Mulvany M.J. Vasodilatation, not hypotension, improves resistance vessel design during treatment of essential hypertension. J. Hypertens. 2001; 19(6): 1001 - 1006.

6. Antonov Ye.V., Alexandrovich Yu.V., Seryapina A.A., Klimov L.0., Markel A.L. Stress and arterial hypertension: ISIAH rat strain. Vavilov Journal of Genetics and Breeding. 2015; 19(4): 455-459. DOI 10.18699/VJ15.060

7. Dovgan R.S.Stechenko L.0.,Zagorodniy M.I.,Chekman I.S.Morphofunctional features of the cardiac myocardial ultrastructure of rats with spontaneous arterial hypertension. Morphology Visn. 2007; 13(2): 255-260.

8. Dovgan R.S. Kolesova N.A., Chekman I.S., Litvinenko V.I., Sukhareva N.M. Influence of biprolol and drugs of metabolic action on the energetics of cardiomyocytes of rats with spontaneous arterial hypertension. Morphology Visn. 2009; 15(1)6: 10.

9. Borisenko A.V., Cherkasova O.V. Structural Changes of the Gingival Blood Vessels in Young Spontaneously Hypertensive Rats under Condition of its Correction with Biprolol, Tiotriazolin and Quercetin. Zap. Medical Journal. 2010; 12(5): 155-157. doi://nbuv.gov.ua/UJRN/Zmzh_2010_12_5_49

10. Taschuk V.K., Solobiukova N.O., Makarov A.A. Meta-Analysis of the Efficacy and Safety of Thiotriazolinum in Acute Coronary Syndrome. Arterial hypertension. 2015; 6: 48-54.

11. Sokurenko L.M., Savchyna M., LitusV.I., Kaminsky R.F., Chaikovsky Yu.B. Rat spinal ganglia in assessment of protective action of antioxidants: A morphological study. Medicina (Kaunas). 2017; 53(4):217-223. doi: 10.1016/j.medici.2017.11.001

12. Sokurenko L.M., Chaikovsky Y.B. Protective Effects of Thiotriazolinum and Mildronate Against Mercury Chloride Toxicity in Neuroblastoma Cell Culture. Neurophysiology. 2016; 48(3): 171-175. doi:10.1007/ s11062-016-9585-7)

13. Chuhray S.M., Lavrynenko V.E., Kaminsky R. F., Dzevulska I.V. et al. Morphofunctional status of cardio-vascular system of rats with congenital hypotireosis. Wiad Lek. 2019; 72(2): 229-233.

14. Chuhray S.M., Lavrynenko V.E., Kaminsky R.F., Ustymenko 0.S. et al.The influence of drug treatment on cardio-vascular system of the rats with congenital hypothyroidism Wiad Lek. 2019, 71, cz. 7, 1300-1303.

15. Chuhray S. M., Lavrynenko V. E., Kaminsky R.F., Dzevulska I. V. et al. Morphofunctional status of cardio-vascular system of rats with arterial hypertension. Wiad Lek. 2020;73(2):355-359. 
16. Karupu V.Ya. Electron microscopy. K.: Vishcha School, 1984: 208.

17. Mazur I.A.,Voloshin N.A., Chekman I.C. Thiotriazolinum. Lviv: Nautilus, 2005; 156 .

18. Dovgan R.S. Kolesova N.A., Chekman I.S., Litvinenko V.I., Sukharev N.M. Influence of biprolol and drugs of metabolic influence on the energetics of cardiomyocytes of rats with spontaneous arterial hypertension. Morph. Visn. 2009; 15(1); 6-10.

19. Christensen K.L., Mulvany M.J. Vasodilatation, not hypotension, improves resistance vessel design during treatment of essential hypertension. J. Hypertens. 2001; 19(6): 1001-1006.

20. Agabiti-Rosei E. Structural and functional changes of the microcirculation in hypertension: influence of pharmacological therapy. Drugs. 2003; 63(1): 19-29.

21. Schiffrin E.L. Vascular changes in hypertension in response to drug treatment: Effects of angiotensin receptor blockers. Can. J. Cardiol. 2002; 18 (Suppl A): 15A-18A.

The authors would like to thank the employees of the Scientific Research Institute Experimental and Clinical Medicine (Institute of Pathologists Problems) at Bogomolets National Medical University prof. L.O. Stechenko and T.P.Kuftyreva.

\section{ORCID and contributionship:}

Svetlana N. Chuhray: 0000-0001-7431-7375 A,B,C

Viktoria E. Lavrynenko: 0000-0002-2570-1271 ${ }^{F}$

Ruzhena M. Matkivska: 0000-0002-4082-2899 ${ }^{B}$

Tetiana V. Lachtadyr: 0000-0003-0223-4866 ${ }^{B}$

Valentina M. Hamalii: 0000-0003-1816-1446 ${ }^{\mathrm{E}}$

Rostyslav F. Kaminsky: 0000-0001-5744-7581 ${ }^{\mathrm{C}}$

Oleksandr I. Kovalchuk: 0000-0002-6311-3518 ${ }^{F}$

Liudmyla M. Sokurenko: 0000-0002-6870-2290 ${ }^{D, E}$

\section{Conflict of interest:}

The Authors declare no conflict of interest.

\section{CORRESPONDING AUTHOR Liudmyla M. Sokurenko}

Bogomolets National Medical University

13 T.Shevchenko st., 01601 Kyiv, Ukraine

tel: +380675010815

e-mail: I-sokurenko@i.ua

Received: 07.11.2019

Accepted: 18.06 .2020
A - Work concept and design, B - Data collection and analysis, C - Responsibility for statistical analysis, D-Writing the article, $\mathbf{E}$-Critical review, $\mathbf{F}$ - Final approval of the article 